\title{
Prediction of cutting tool vibration and surface roughness in hard turning of AISI52100 steel
}

\author{
Nitin Ambhore ${ }^{1,2, *}$, Dinesh Kamble ${ }^{1}$, and Satish Chinchanikar ${ }^{1}$ \\ ${ }^{1}$ Mechanical Engineering Department, Vishwakarma Institute of Information Technology, 411048, SP \\ Pune University, Pune, India \\ ${ }^{2}$ Research Scholar, Mechanical Engineering Department, Sinhgad College of Engineering, 411046, \\ SP Pune University, Pune, India
}

\begin{abstract}
The changing behavior of vibration signals with varying cutting parameters (cutting speed, feed rate and depth of cut) for turning hardened AISI52100 steel has been studied and reported. The vibration response of cutting tool in all three mutually perpendicular directions, namely, in feed $\mathrm{Vx}$, radial $\mathrm{Vy}$ and, tangential $\mathrm{Vz}$ directions have been captured by mounting piezoelectric tri-axial accelerometer close to the cutting tool. Experiments are planned and conducted as per Central composite rotatable design of Surface response methodology. The second order multiple regression models are developed to correlate cutting parameters with vibration acceleration and surface roughness. The coefficient of regression $\mathrm{R}^{2}$ for all models is found close to 0.92 which shows that the developed models are reliable and provide an excellent explanation between the cutting parameter and the vibration of cutting tool within limits. The analysis of the results revealed that cutting conditions are having prominent and mixed type effect on vibration signals. The acceleration amplitude $\mathrm{Vx}, \mathrm{Vy}$ and $\mathrm{Vz}$ increases with increase in cutting speed, and depth of cut. The vibration amplitude $\mathrm{Vx}, \mathrm{Vy}$ and $\mathrm{Vz}$ initially increases as feed increases and, with further increase in feed, the vibration amplitude decreases. The surface roughness is highly influenced by the feed rate followed by cutting speed whereas the depth of cut was found less significant. The fluctuation in frequency is observed in all directions. However, the band of frequency remains within a certain range. Within selected cutting parameter range, the maximum acceleration amplitude is observed in frequency band of $4 \mathrm{kHz}-16 \mathrm{kHz}$.
\end{abstract}

\section{Introduction}

A metal cutting system, in general, is consisting of the machine tool, cutting tool and the workpiece that have a very complicated dynamic characteristic and as a result, vibration frequently occurs under certain machining conditions. In turning process, three types of vibration are observed, free, forced and self-excited vibrations [1]. Cutting tool vibrations are continuously generated during turning since the tool has physical contact with the work-

* Corresponding author: nitin.ambhore@gmail.com 
piece. When turning hardened steel with hardness 45-70 HRC, the cutting tool is subjected to a heavy mechanical load which leads to increase in vibrations. The presence of vibration is major issue which directly affects the surface quality of a product, the performance of tool, tool life and create unpleasant noise in the working environment [2-3]. The engagement and disengagement of cutting tool during machining play a notable role in the vibration produced. A non-homogeneity and properties variation in the workpiece material also increases the vibration in a metal cutting process [4]. Therefore, the vibration induced during turning is complicated and required to be addressed properly.

Nowadays, piezoelectric accelerometers are widely used to measure the acceleration of vibrating body. With the help of Fast Fourier Transform (FFT) analyzer, acceleration signals are analyzed and converted into frequency domain from time domain [5]. From the literature, it can be seen that vibration signals have been analyzed for predicting surface finish and, also used to monitor the tool wear. However, very few efforts have been made in understanding the behavior of cutting tool vibrations with the progress of tool wear. Balla et al. [6] investigated the correlation between displacement amplitude and tool wear for different hardness levels, in the turning of AISI 4140 steel using uncoated carbide tool. They developed multiple linear regression models and $\mathrm{R}^{2}$ value 0.9 is observed. The ANOVA study showed that the displacement factor is influenced by the cutting speed, depth of cut and the workpiece hardness. Gonzalez et al. [5], analyzed vibration signals for different tool wear state using RMS and FFT spectral analysis. They observed from FFT analysis that acceleration level at some frequencies with increasing tool flank wear. They also observed that signal amplitude is influenced by workpiece diameter. Acceleration amplitude decreases in frequency spectra with decreases in workpiece diameter for constant cutting parameters.

Bhuiyan et al. [7] experimentally investigated chip formation, tool wear and surface roughness under different cutting conditions using vibration signature during turning of ASSAB-705 steel. The results of their study revealed that vibration components can effectively respond to the different occurrences in turning including tool wear and surface roughness. The amplitude of vibration components $\mathrm{Vx}, \mathrm{Vy}$ and $\mathrm{Vz}$ increased with the increase of feed rate, depth of cut and cutting speed respectively. Alonso et al. [8] reported singular spectrum analysis and cluster analysis techniques for analyzing vibration signals capture during turning. The results showed that the vibration signals provide useful information about tool condition in certain frequency bandwidth. The flanks wear related information in the vibration signals contained in the high frequencies and in only certain low-frequency components. D'Mello et al. [9] concluded that tool flank wear is highly influenced by cutting parameters, and with the increase in flank wear, surface finish has been improved. Cutting tool vibrations along tangential direction showed a direct correlation with surface roughness parameters, and surface roughness is highly influenced by cutting parameters. Abouelatta et al. [10] analyzed vibration signals by FFT analyzer and developed regression models to correlate surface roughness with cutting tool vibration. The tool vibration was measured in feed and radial directions using a tri-axial accelerometer mounted near to the tip and connected to the FFT analyzer. $\mathrm{R}^{2}$ values of the proposed models were fairly accurate. The experimental result of their study suggested that consideration of tool vibration and cutting force together increases the accuracy of a model. Similar observations were also reported by Kirby et al. [11].

In another study, Zahia et al. [12] also investigated the combined effects of cutting parameters and tool vibration on surface roughness while turning $42 \mathrm{CrMo} 4$ hardened steel using $\mathrm{Al}_{2} \mathrm{O}_{3} / \mathrm{TiC}$ coated ceramic tool. Their study indicates that the feed rate is the dominant factor affecting the surface roughness, whereas vibrations on both tangential and radial directions have a low effect on it. Chen et al. [13] developed logistic regression model by using vibration signals and presented a new reliability estimation approach to the 
cutting tool. The characteristics of measured parameters have been studied using signal processing techniques and integrated in a logistic regression model to evaluate the reliability of lathe cutting tools. Their study concluded that the reliability indices and failure time of the tool can be accurately assessed by using the obtained model.

In the present work, the changing behavior of vibration signals with varying cutting parameters (cutting speed, feed rate and depth of cut) for turning hardened AISI52100 steel has been studied and reported.

\section{Experimental procedures}

The workpiece material used in this study was hardened AISI52100 steel with a hardness of 54 HRC. The cylindrical bars with $62 \mathrm{~mm}$ diameter (D) and $450 \mathrm{~mm}$ cutting length (L) were selected to achieve L/D ratio less than 10 as per ISO 3685 standards [14]. The hardened steel rods were trued, centred, and cleaned on the CNC lathe machine for small depth of cut at a moderate machining speed and feed. The chemical composition of the work-piece material is found as: $1.03 \% \mathrm{C}, 1.38 \% \mathrm{Cr}, 0.35 \% \mathrm{Mn}, 0.16 \% \mathrm{Si}, 0.002 \% \mathrm{P}, 0.005 \% \mathrm{~S}$ and balance Fe.

Central Composite Rotatable Design (CCRD) method of Response surface methodology is used for designing the experimental runs. Experiments were carried out in dry condition using SimpleTurn5076 CNC lathe. The lathe is equipped with $7.5 \mathrm{~kW}$ spindle power and maximum spindle speed of $2000 \mathrm{rpm}$. The coated carbide tool insert is selected of ISO designation CNMG120408-MF5 with TH1000 grade. A Bruel \& Kjaer 4535B001 Type 30859 tri-axial piezoelectric accelerometer with sensitivity $9.8 \mathrm{mV} / \mathrm{g}$ is mounted on tool holder as close as possible to the tool insert to measures vibration of cutting tool in three mutually perpendicular directions, feed $(\mathrm{Vx})$, $\operatorname{radial}(\mathrm{Vy})$ and tangential $(\mathrm{Vz})$. The accelerometer signals are taken to Bruel and Kjaer four channel signal analyzer type LDS DACTRON and RT Pro PHOTON Dynamic Signal Analysis Software. The cutting parameters, namely, cutting speed, feed and depth of cut, are selected on the basis of preliminary experiments, literature review and tool manufacturer's recommendation. The range of cutting parameters selected for turning experiments are shown in Table 1.

Table 1. Cutting parameters and levels

\begin{tabular}{|c|c|c|c|c|c|}
\hline \multirow{2}{*}{ Parameters } & \multicolumn{5}{|c|}{ Levels } \\
\cline { 2 - 6 } & 1.68 & 1 & 0 & 1 & 1.68 \\
\hline Cutting speed V, (m/min) & 60 & 90 & 120 & 150 & 180 \\
\hline Feed f, (mm/rev) & 0.1 & 0.2 & 0.3 & 0.4 & 0.5 \\
\hline Depth of cut d, (mm) & 0.1 & 0.2 & 0.3 & 0.4 & 0.5 \\
\hline
\end{tabular}

In each cutting condition, a fresh cutting tool was used and machining was carried out. The process parameters such as acceleration and surface roughness have been measured. This process was repeated till the failure of the cutting tool.

\section{Experimental Results and Discussions}

The objective of the present work is to understand the influence of the cutting parameters namely cutting speed, feed rate and depth of cut on cutting tool vibrations and surface roughness. The ANOVA and statistical analysis treatment is performed on obtained results using Design Expert Statistical Software package. The correlation between input parameters $(\mathrm{V}, \mathrm{f}, \mathrm{d})$ and response parameters $(\mathrm{Ra}, \mathrm{Vx}, \mathrm{Vy}, \mathrm{Vz})$ are developed by multiple regression equations. The obtained equations (1-4) are as follows,

$R a=16.8701-0.1491 \times V-28.4432 \times f-15.34347 \times d+0.23869 \times V \times f$

$+0.01417 \times V \times d+1.6475 \times f \times d+0.00029 \times V^{2}+4.95640 f^{2}+21.38640 \times d^{2}$ 


$$
\begin{aligned}
& V x=-0.54072+6.22191 \times 10^{-3} \times V+0.86238 \times f+0.76964 \times d-1.00954 \times 10^{-3} \times V \times f \\
& -1.33046 \times 10^{-3} \times V \times d+0.16846 \times f \times d-2.23224 \times 10^{-5} \times V^{2}-1.45864 \times f^{2}-1.09714 \times d^{2} \\
& V y=-0.27961+4.00862 \times 10^{-3} \times V-0.19348 \times f+0.69139 \times d+5.90113 \times 10^{-3} \times V \times f \\
& -1.41646 \times 10^{-3} \times V \times d+0.16256 \times f \times d-2.17083 \times 10^{-5} \times V^{2}-0.69445 \times f^{2}-0.80995 \times d^{2} \\
& V z=-0.43577+4.42197 \times 10^{-3} \times V+0.68063 \times f+1.08266 \times d+4.93181 \times 10^{-3} \times V \times f \\
& -3.82475 \times 10^{-4} \times V \times d-0.97646 \times f \times d-2.40957 \times 10^{-5} \times V^{2}-1.75364 \times f^{2}-1.21239 \times d^{2}
\end{aligned}
$$

The $\mathrm{R}^{2}$ value of above models is found close to 0.92 , which shows that the developed models are reliable and provide an excellent explanation between the cutting parameter and the vibration of cutting tool within limits. These models can be used to predict vibration induced during hard turning. The behavior of cutting tool vibrations measured along the cutting direction (tangential), feed direction and radial direction is shown in Fig.1.
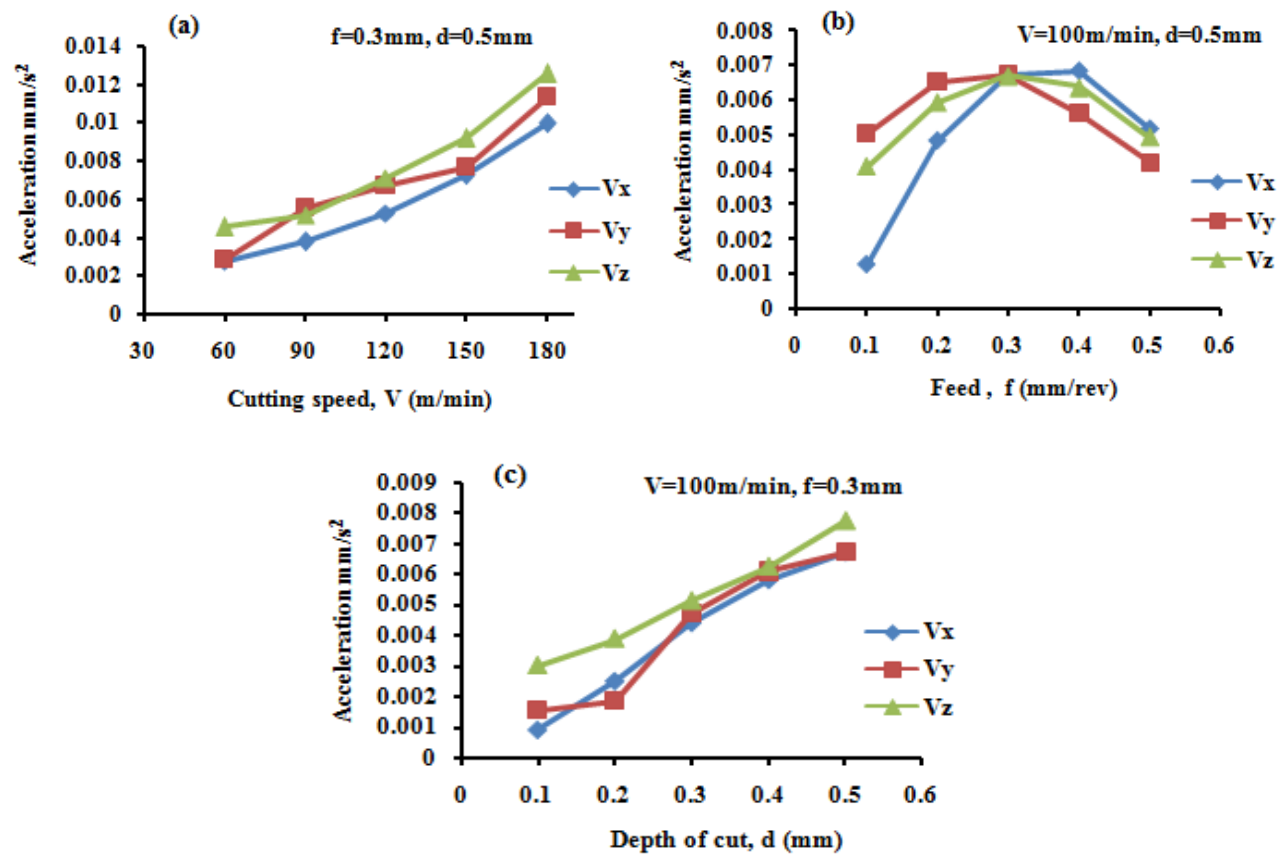

Fig. 1 Effect of cutting parameters on cutting tool vibration

Fig. 1(a) illustrates the effect of varying cutting speed on vibration in a feed(Vx), radial(Vy) and tangential $(\mathrm{Vz})$ directions at a constant feed rate of $0.3 \mathrm{~mm}$ and depth of cut $0.5 \mathrm{~mm}$. It can be observed that vibration signals increase as cutting speed increases in a selected parameters range. The experimental works of some researchers have shown a similar trend of vibration signals for cutting speed. However, some of the researchers found decreasing trend for high speed turning. Fig. 1(b) represents the effect of varying feed on vibration at cutting speed of $100 \mathrm{~mm} / \mathrm{min}$ and depth of cut $0.5 \mathrm{~mm}$ and can be observed that vibration signals increase for lower values of feed and decrease with further increase in feed rate. Fig. 1(c) represents the effect of varying depth of cut on vibration at cutting speed of $100 \mathrm{~mm} / \mathrm{min}$ and feed $0.3 \mathrm{~mm} / \mathrm{rev}$ and it can be observed that vibration signals increase as the depth of cut increases. This is in good agreement with Suresh et al. [15] and Asilturk 
et al. [16]. From Fig. 1(a-c), the mixed type fluctuation in vibration is observed. This could be because of gradual tool wear and different chips formation types. Fig. 2 shows a variation of acceleration amplitude in feed $(\mathrm{Vx})$, radial $(\mathrm{Vy})$ and tangential $(\mathrm{Vz})$ directions for cutting speed $120 \mathrm{~m} / \mathrm{min}$, feed $0.3 \mathrm{~mm} / \mathrm{rev}$ and depth of cut $0.3 \mathrm{~mm}$. Acceleration amplitude increases as the number of passes (cutting time) increases due to gradual increases in tool wear.

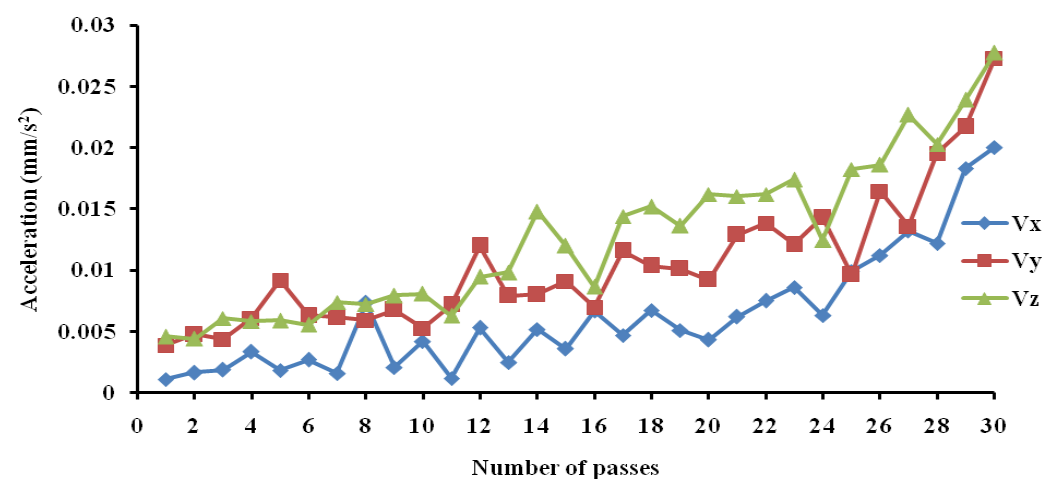

Fig. 2 Effect of cutting parameters on cutting tool vibration

It is also observed that vibration signal fluctuates between $35 \mathrm{~Hz}$ to $19 \mathrm{kHz}$, whereas the maximum acceleration is found in frequency band from $4 \mathrm{kHz}$ to $16 \mathrm{kHz}$. The trends of all the graphs are in good agreement with Bhuiyan et al. [17]. Increasing trend is observed because of progression of tool wear.

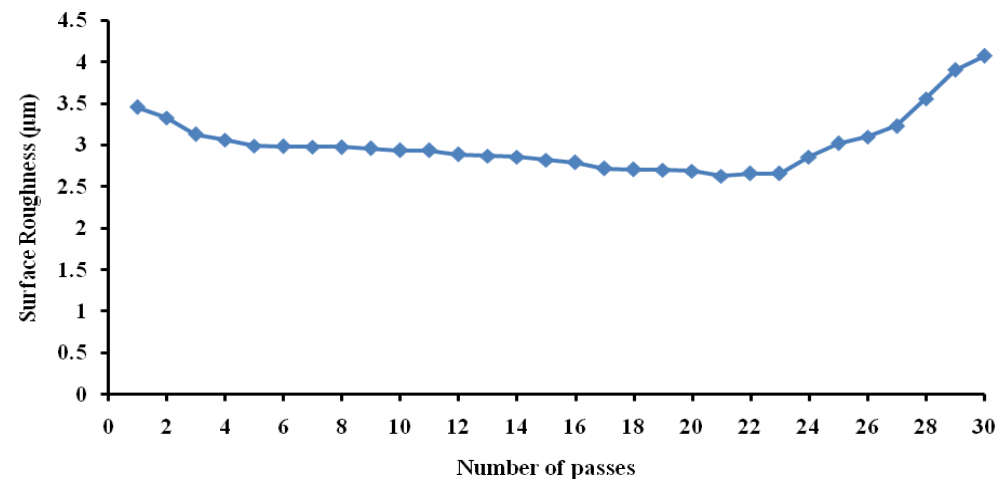

Fig. 3 Effect of cutting parameters on surface roughness

Fig. 3 represents a variation of surface roughness for cutting speed $120 \mathrm{~min} / \mathrm{min}$, feed 0.3 $\mathrm{mm} / \mathrm{rev}$ and depth of cut $0.3 \mathrm{~mm}$. In the initial stage, the surface roughness decreases drastically and this could be because of sharp edges of the cutting tool. In the second stage, uniform variation in surface roughness is observed due to uniform wear rate. In the last stage, roughness further increases due to the cutting tool wears out at a higher rate. From the ANOVA result, it is observed that surface roughness is highly influenced by the feed rate followed by cutting speed whereas the depth of cut was found less significant. 


\section{Conclusions}

In this work, an experimental investigation has been carried out to understand the influence of the cutting parameters namely cutting speed, feed rate and depth of cut on cutting tool vibrations and surface roughness. The coefficient of regression $\mathrm{R}^{2}$ for all models is found close to 0.92 which shows that the developed model is reliable and provides an excellent explanation between the cutting parameter and the vibration of cutting tool within limits. It has been observed that acceleration amplitude $\mathrm{Vx}, \mathrm{Vy}$ and $\mathrm{Vz}$ increases with increase in cutting speed, and depth of cut. The vibration amplitude Vx, Vy and Vz initially increases as feed increases and, with further increase in feed, the vibration amplitude decreases. The surface roughness is highly influenced by the feed rate followed by cutting speed whereas the depth of cut was found less significant. The fluctuation in frequency is observed in all directions.

\section{References}

[1] D. E. Dimla, Snr., Int. J Adv Manuf. Technol. 19 705-713 (2002)

[2] S. K. Shihab, Z. A. Khan, A. Mohammad, A. N. Siddiquee, Prod. \& Manuf. Research: An Open Access Journal 2(1) 24-49 (2014)

[3] R. Serra, W. Rmili, Int. J. of Acoustics and Vibration, 21(1) 50-58 (2016)

[4] R. Teti, K. Jemielniak, G. O’Donnell, D. Dornfeld, CIRP Annals - Manuf. Technol., 79 717-739 (2010)

[5] A. Gonzalez-Laguna, J. Barreiro, A. Fernandez-Abia, E. Alegre, V. Gonzalez- Castro, Procedia Engineering 132 405-412 (2015)

[6] S. P. Balla, M. P. Babu, Engineering Science and Technology, an International Journal 2017, 20, 197-211.

[7] M. S. H. Bhuiyan , I. A. Choudhury, Machining Sci. and Technol., 19:2 236261(2015)

[8] F. J. Alonso, D. R. Salgado, Mechanical Systems and Signal Processing, 22 735-748 (2008)

[9] G. D’Mello, P. P. Srinivasa, N. P. Puneet, F. Ning, Int. J. of Machining and Machinability of Materials, 18(3) 288-312 (2016)

[10] O. B. Abouelatta, J. Madl, J. of Material Processing Technol., 118 269-277 (2001)

[11]E. D. Kirby, Z. Zhang and J. C. Chen, J. of Indu. Technol., 20(4) 1-8 (2004)

[12]H. Zahia, A. Belbah, M. A. Yallese, T. Mabrouki, J. Rigal, Measurement, 46 16711681 (2013)

[13]B. Chen, X. Chen, B. Li, Z. He, H. Cao, G. Cai, Mechanical Systems and Signal Processing, 255 2526-2537 (2011)

[14] International Organization for Standardization. Tool-life testing with single point turning tools, ISO 3685-1993 (E), 2nd Edition, Case Postale 56, CH-1211 Geneve 20, Switzerland.

[15]R. Suresh, S. Basavarajappa, G. L. Samuel, Measurement, 45 1872-1884 (2012)

[16]I. Asilturk, H. Akkus, Measurement 44 1697-1704 (2011)

[17] M. S. H. Bhuiyan, I. A. Choudhury, M. Dahari, J. of Manuf. Systems, 33(4) 476-487 2014 